\title{
Ethylene and Polyamine Metabolism in Climacteric and Nonclimacteric Carnation Flowers
}

\author{
M. Serrano and F. Romojaro \\ Centro de Edafología y Biología Aplicada del Segura, Avenida de la \\ Fama, 1, Murcia 30080, Spain
}

J.L. Casas and M. Acosta

Departamento de Biología Vegetal (Fisiología Vegetal), Universidad de

Murcia, Santo Cristo, 1, Murcia 30001, Spain

Additional index words. 1-aminocyclopropane-1-carboxylic acid, EFE activity, longevity, putrescine, spermidine, Dianthus caryophyllus

Abstract. We have compared the ethylene and polyamine metabolism of senescing flowers from two cultivars of carnation (Dianthus caryophyllus L.), one showing climacteric ('Arthur') and the other non climacteric behavior ('Killer'). 'Arthur' carnations showed the first symptoms of senescence at day 7 , coinciding with maximum ethylene and $\mathrm{CO}_{2}$ production, a peak in the ethylene-forming enzyme (EFE) activity, and a 7-fold increase in free ACC content in respect to the initial value. In 'Killer' carnations, however, onset of senescence was 15 days after harvest, and no ethylene or $\mathrm{CO}_{2}$ peak was detected. The lack of ethylene production was due to a constantly low level of free ACC and a low EFE activity. Free polyamine distribution was similar in the two cultivars at the preclimacteric stage, with the spermidine content being about three times that of putrescine. But as senescence progressed, this situation was reversed in 'Arthur' carnation, with a predominance of putrescine during the senescence, while it was maintained in 'Killer', with no significant changes during senescence. No free spermine was found at any stage of senescence in either cultivar. Thus, a correlation exists between ACC level, distribution of polyamides, and longevity of cut carnation flowers. Chemical name used: 1-aminocyclopropane-1-carboxylic acid (ACC).

Senescence in plant tissues is linked to many biochemical and physiological changes. The existence of a significant increase in ethylene production and respiration rate at the beginning of senescence is used to distinguish between climacteric and nonclimacteric senescence.

Ethylene is synthesized from methionine through the conversion of S-adenosylmethionine (SAM) into ACC and a subsequent breakdown of ACC to yield ethylene. These two reactions are catalyzed by ACC synthase and the ethylene-forming enzyme (EFE), respectively (Yang and Hoffman, 1984). This pathway is very active during the senescence of climacteric fruits and flowers but not in nonclimacteric tissues or organs.

SAM may be used not only for ethylene biosynthesis, but also in other biosynthetic reactions, including polyamides. The functions of polyamides and ethylene differ diametrically. Thus, while ethylene production is enhanced in processes such as fruit ripening, leaf abscission, or flower senescence (Yang and Hoffman, 1984), polyamides are predominant in young tissues or during ac-

Received for publication 14 Sept. 1990. Work supported by funds from Comisión Interministerial de Ciencia y Tecnología, Project ALI89-0293. The cost of publishing this paper was defrayed in part by the payment of page charges. Under postal regulations, this paper therefore must be hereby marked advertisement solely to indicate this fact.
Cut carnation flowers are usually a climacteric system, where enhanced ethylene production and respiration rates are associated with the onset of senescence. We here report the relationship between ethylene and polyamine content in senescing flowers of two cultivars of carnation, one exhibiting climacteric and the other nonclimacteric behavior. The possible relationship between both growth regulators and the longevity of the flowers is discussed.

'Arthur' and 'Killer' carnation flowers were obtained from a local greenhouse (Barberet and Blanc, Puerto Lumbreras (Murcia), Spain). Once in the laboratory, the flowers were trimmed to a $20-\mathrm{cm}$ stem length and placed individually in test tubes containing distilled water. The environmental conditions maintained throughout the experiments were 20 to $22 \mathrm{C}, 70 \%$ to $75 \%$ relative humidity $(\mathrm{RH})$, and a 12-h photoperiod with white fluorescent light $\left(74.5 \mu \mathrm{mol} \cdot \mathrm{s}^{-1} \cdot \mathrm{m}^{-2}\right)$. To measure ethylene and $\mathrm{CO}_{2}$ production, cut carnations were individually enclosed in 350-ml glass jars for $1 \mathrm{~h}$. A 1-ml gas sample was then withdrawn and ethylene concentration determined by gas chromatography (Cromatix KNK-2000; Konik S.A., Barcelona, Spain). Carbon dioxide production by the flowers was measured by injecting another 1-ml gas sample from the same jar into a nondispersive infrared analyzer (Model 865; Beckman Instruments).

Total (free and conjugated) ACC was extracted according to Atta-Aly et al. (1987) with slight modifications. Carnation petals were macerated in a mortar with pestle in $0.2 \mathrm{M}$ trichloroacetic acid $(1: 3, \mathrm{w} / \mathrm{v})$. The macerate was centrifuged at $7000 \times g$ for 10 min, and the supernatant was used to determine its free ACC content. Conjugated ACC was hydrolyzed to free ACC according to Hoffman et al. (1983). In both cases, the quantification of ACC was made according to Lizada and Yang (1979).

EFE activity was measured in petals from the two external whorls of the carnations. Petals were enclosed in vials with $25 \mathrm{~mm}$ Tris-Hepes buffer, $\mathrm{pH} 7.5$, containing $1 \mathrm{~mm}$ ACC. After $4 \mathrm{~h}$ at $30 \mathrm{C}$ and continuous shaking, a gas sample of the vial atmosphere was withdrawn and monitored for its ethylene content by gas chromatography. Petals kept only in buffer were taken as control.

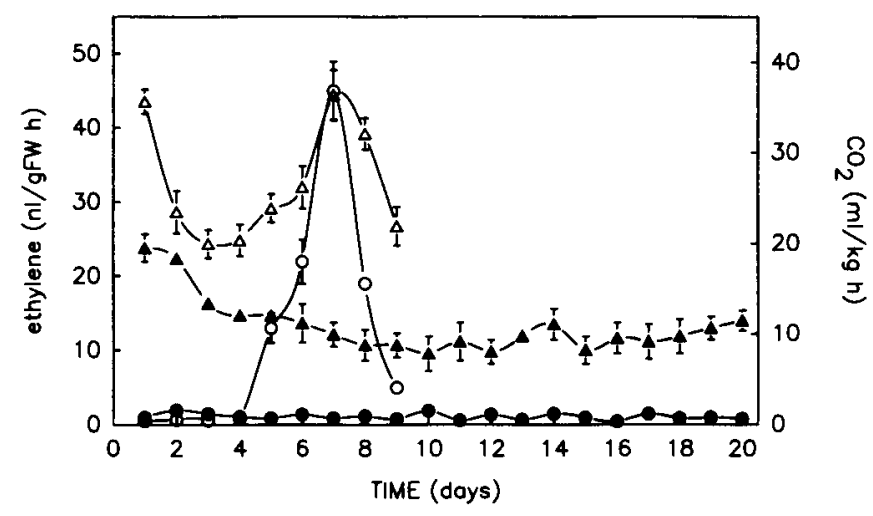

Fig. 1. Ethylene $(\mathrm{O})$ and $\mathrm{CO}_{2}(\Delta)$ production during senescence of 'Arthur' (open symbols) and 'Killer' (filled symbols) carnation flowers. Values are the mean of 10 flowers. Standard error is shown when larger than symbols. 


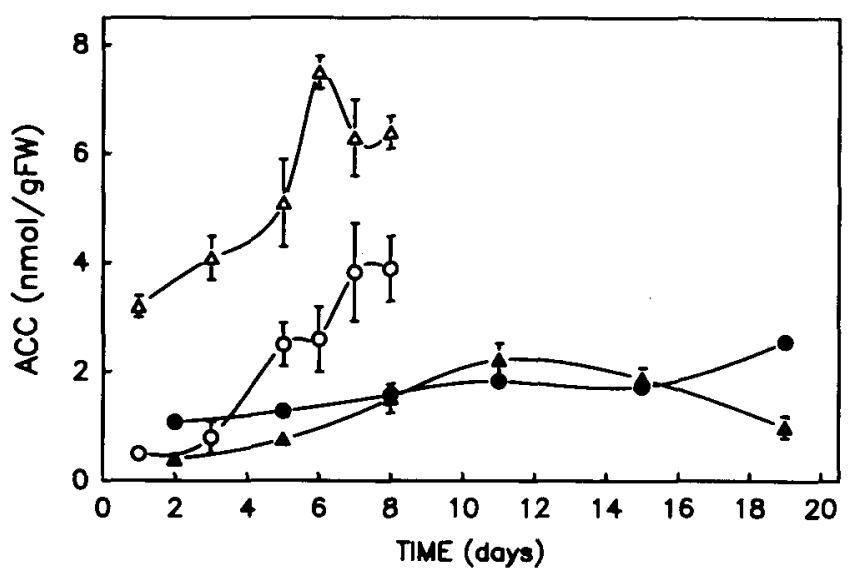

Fig. 2. Free $(O)$ and conjugated $A C C(\triangle)$ content of petals during senescence of 'Arthur' (open symbols) and 'Killer' (filled symbols) carnation flowers. Values are the means of three replicates of

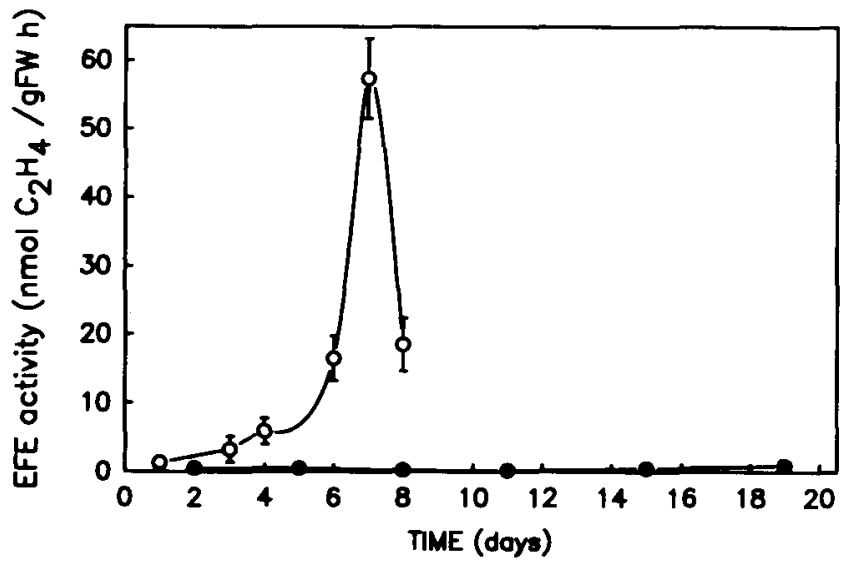

Fig. 3. EFE activity during senescence of 'Arthur' $(O)$ and 'Killer' $(\bullet)$ carnation flowers. Values are the means of three replicates of three flowers each. Standard error is shown when larger than symbols.

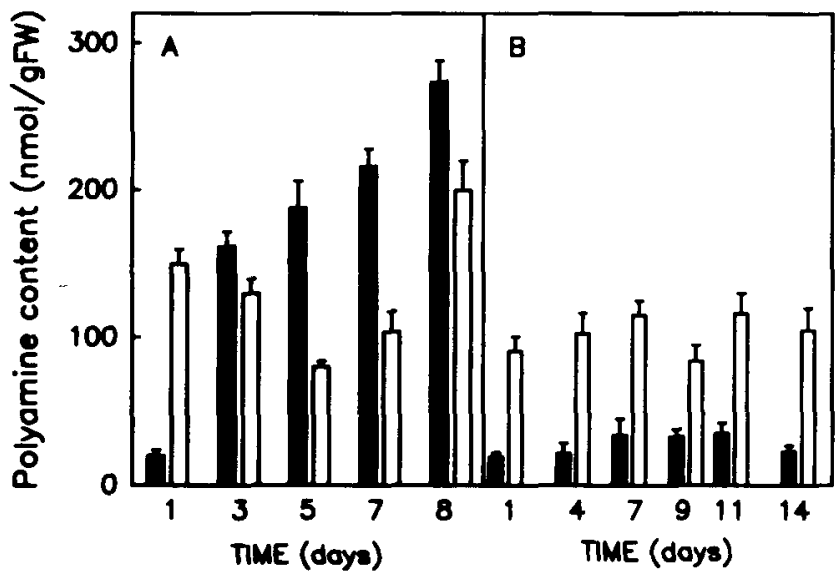

Fig. 4. Putrescine ( $\mathbf{D})$ and spermidine ( $\square$ ) content during senescence of 'Arthur' (A) and 'Killer (B) carnation flowers. Values are the means of three replicates of three flowers each and $1 / 2$ standard error is shown.

Polyamines were extracted according to Flores and Galston (1982) and analyzed by the benzoylation method according to Redmond and Tseng (1979), with slight modifications. Two milliliters of $4 \mathrm{~N} \mathrm{NaOH}$ was mixed with $2 \mathrm{ml}$ of the $\mathrm{HClO}_{4}$ extract and $20 \mu$ of benzoyl chloride. After vortexing for $15 \mathrm{sec}$, the mixture was incubated for 20 min at room temperature. Four milliliters of saturated $\mathrm{NaCl}$ was then added and the benzoyl-polyamines extracted with $4 \mathrm{ml}$ of cold diethyl ether for $30 \mathrm{~min}$ at $-18 \mathrm{C}$. Finally, $2 \mathrm{ml}$ of the ether phase was evaporated under nitrogen and redissolved in $1 \mathrm{ml}$ of methanol (HPLC grade). In all the steps, only plastic vials were used.
The chromatographic system consisted of methanol/water as solvent run isocratically at $53 \%$ methanol, with a flow rate of 0.8 $\mathrm{ml} \cdot \mathrm{min}^{-1}$. The benzoyl-polyamines were eluted at room temperature through a 5- $\mu$ mparticle-size reversed-phase column $(\mu$ Bondapak $\mathrm{C}_{18}$ ) and detected by absorbance at $254 \mathrm{~nm}$. Quantification of the polyamine levels was made using hexanediamine as internal standard.

'Arthur' and 'Killer' carnations differed greatly in their respiratory and ethylene production patterns (Fig. 1). After an initial period of low basal ethylene production in 'Arthur' carnations, a pronounced peak of ethylene synthesis was registered at day 7 . This peak coincided with a similar rise in the respiratory activity and the appearance of the typical symptoms of senescence, such as petal inrolling and wilting. In 'Killer' carnations, ethylene production and respiratory activity were very low and did not change significantly during senescence (Fig. 1). Also, darkening and drying of petals (the first symptoms of senescence in these carnations) was delayed 8 days with respect to 'Arthur' carnations.

In 'Arthur' carnations, the free ACC content was initially low but accumulated within the tissue during senescence, reaching a final value eight times greater than the initial. Conjugated ACC was initially higher than free ACC in this cultivar and also accumulated during senescence, but with a final value only two times greater than the initial (Fig. 2). Conversely, in petals of 'Killer' carnations, the free and conjugated ACC contents were low and almost stable during senescence, with only a slight increase in free ACC, concurrent with a decrease in conjugated ACC at day 19 (Fig. 2).

EFE activity in 'Arthur' carnations was very low during the preclimacteric stages but increased along with ethylene production, peaking at day 7 (Fig. 3). In 'Killer' carnations, however, the EFE activity of the petals was very low throughout senescence (Fig. 3).

These results show that the lack of ethylene production in 'Killer' carnations was due to a combination of two causes: 1) limited available ACC likely resulting from low ACC synthase activity, and 2) failure to convert ACC into ethylene because of restricted EFE activity.

Polyamides have been identified as antisenescent agents (Evans and Malmberg, 1989). There is evidence that exogenously applied polyamides might exert an antisenescent effect on various systems, such as excised oat (Altman et al., 1977; Kaur-Sawhney et al., 1982) or barley leaves (Srivastava et al., 1983). However, unexpectedly, the exogenous application of polyamides did not increase the longevity of cut carnation flowers (Downs and Lovell, 1986). These contradictory data suggest the existence of a very fine control system regulating the endogenous level of polyamides. In view of this, we investigated whether important variations in polyamine levels between the two cultivars could account for such a big dif- 
ference in longevity and ACC metabolism.

Putrescine (Put) and spermidine (Spd) were the major polyamides found during the senescence of both cultivars. Appreciable differences were found, however, in the accumulation pattern between 'Arthur' and 'Killer' carnations. Thus, Put content in 'Arthur' increased continuously from 20 nmols. ${ }^{-1}$ of fresh weight found at day 1 to $\approx 270$ in a very advanced stage of senescence (Fig. 4A). However, Put content in 'Killer' remained almost steady at $\approx 30 \mathrm{nmols} \cdot \mathrm{g}^{-1}$ of fresh weight (Fig. 4B). Spd content was initially higher "than Put in 'Arthur', but decreased until day 6 , when it increased again until the end of senescence, in a very similar manner to that reported by Roberts et al. (1984). The opposite situation was found in 'Killer' carnations, where Spd content was always about 3 times higher than that of Put. Again, no significant variations in Spd level, except a slight decrease at day 9 , were found in this cultivar.

If we consider the total amount of free polyamides (Put + Spd), the nonclimacteric cultivar ('Killer') had a high percentage of Spd, between $72 \%$ and $83 \%$ of the polyamines found during senescence. 'Arthur' carnations showed a similarly high percentage of Spd $(89 \%)$ only at the first stage of senescence, when the flowers were still young, but at the climacteric peak of ethylene production, this was reduced to almost $30 \%$ of total. This ability of 'Killer' carnations to remain physiologically young may be connected with their longevity.

The results presented here show that the physiology of climacteric and nonclimacteric senescence is quite different, not only in regard to ethylene metabolism, but also for polyamine metabolism. Furthermore, 'Killer' carnations have been shown to be a very useful tool in investigating the mechanisms involved in cut carnation senescence and in the regulation of the ethylene and polyamine biosynthetic pathways.

\section{Literature Cited}

Altman, A., R. Kaur-Sawhney, and A.W. Galston. 1977. Stabilization of oat leaf protoplasts through polyamine mediated inhibition of senescence. Plant Physiol. 60:570-574.

Atta-Aly, M.A., M.E. Saltveit, Jr., and G.E. Hobson. 1987. Effect of silver ions on ethylene biosynthesis by tomato fruit tissue. Plant Physiol. 83:44-48.

Bakanashvili, M., R. Barkai-Golan, E. Kopeliovitch, and A. Apelbaum. 1987. Polyamine biosynthesis in Rhizopus-infected tomato fruits: Possible interaction with ethylene. Physiol. Molec. Plant Pathol. 31:41-50.

Casas, J.L., M. Acosta, J.A. Del Río, and F. Sabater. 1990. Ethylene evolution during ripening of detached tomato fruit: Its relation with polyamine metabolism. Plant Growth Regulat. 9:89-96.

Dibble, A.R.G., P.J. Davies, M.A. Mutschler, and P.W. Zimmerman. 1988. Polyamine content of long-keeping alcobaca tomato fruit. Plant Physiol. 86:338-340.

Downs, G.C. and P.H. Lovell. 1986. The effect of spermidine and putrescine on the senescence of cut carnations. Physiol. Plant. 66:679-684.

Evans, P.T. and R.L. Malmberg. 1989. Do polyamides have roles in plant development? Annu.
Rev. Plant Physiol. Plant Molec. Biol. 40:235269.

Flores, H.E. and A.W. Galston. 1982. Analysis of polyamides in higher plants by high performance liquid chromatography. Plant Physiol. 69:701-706

Hoffman, N.E., Y. Liu, and S.F. Yang. 1983. Changes in 1-(malonylamino)cyclopropane-1carboxylic acid content in wilted wheat leaves in relation to their ethylene production rates and 1-aminocyclopropane-1-carboxylic acid content. Planta 157:518-523.

Kaur-Sawhney, R., L.M. Shih, H.E. Flores, and A.W. Galston. 1982. Relation of polyamine synthesis and titer to aging and senescence in oat leaves. Plant Physiol. 69:405-410.

Lizada, M.C.C. and S.F. Yang. 1979. A simple and sensitive assay for 1-aminocyclopropane-1carboxylic acid. Anal. Biochem. 100: 140-145.

Redmond, J.W. and A. Tseng. 1979. High pressure liquid chromatographic determination of putrescine, cadaverine, spermidine and spermine. J. Chrom. 170:479-481.
Roberts, D.R., M.A. Walker, J.E. Thompson, and E.B. Dumbroff. 1984. The effects of inhibitors of polyamine and ethylene biosynthesis on senescence, ethylene production and polyamine levels in cut carnation flowers. Plant Cell Physiol. 25:315-322.

Smith, T.A. 1985, 1986. Polyamides. Annu. Rev. Plant Physiol. 36:117-143.

Srivastava, S.K., D.J. Vashi, and B.I. Naik. 1983. Control of senescence by polyamides and guanidines in young and mature barley leaves. Phytochemistry 22:2151-2154.

Toumadje, A. and D. Richardson. 1988. Endogenous polyamine concentrations during development, storage and ripening of pear fruits. Photochemistry 27:335-338.

Winer, L. and A. Apelbaum. 1986. Involvement of polyamides in the development and ripening of avocado fruits. J. Plant Physiol. 126:223233.

Yang, S.F. and N.E. Hoffman. 1984. Ethylene biosynthesis and its regulation in higher plants. Annu. Rev. Plant Physiol. 35:155-189. 